\title{
10. Competing with Business Analytics: Research in progress
}

\author{
Harjot Singh Dod \\ University of Melbourne \\ Rajeev Sharma \\ University of Melbourne
}

\begin{abstract}
Gaining competitive advantage is the focus of any organisation operating in today's marketplace. With readily available integrated data from data warehouses and innovation in business intelligence tools, managers are well placed to make smart decisions and hence better the competitive advantage of their firms. Only a few organisations have been able to fully realise the potential of business analytics (BA). A part of the reason could be a lack of understanding as to how business analytics can provide competitive advantage. A brief literature review on the topic of business analytics, which tries to capture the relevant research in this field, is presented. Literature on theory building is also analysed in order to provide a secure basis for the intended future research.
\end{abstract}

\section{Introduction}

Business analytics (BA) is a new and upcoming field in information systems (IS) research. Kohavi et al. (2002) argue that the strategic value of business analytics has led to significant development of business applications in areas that analyse customer data. These applications have been used to 'reduce customer attrition, improve customer profitability, increase the value of e-commerce purchases, and increase the response of direct mail and email marketing campaigns' (Kohavi et al., 2002, p. 47). Applications in other areas like finance, marketing, production, manufacturing, human resources and research and development have also been described in the literature (Davenport, 2006; Kohavi et al., 2002; Sharma et al., 2010). It has been argued that organisations will be able to create competitive advantage with the use of business analytics (Davenport, 2006). These claims are yet to be explained theoretically and researchers are trying to build theoretical models for the same (Sharma et al., 2010). The aim of this chapter is to review 
recommendations from the existing theory-building literature and analyse their significance for future theory-building initiatives to explain BA and its effect on competitive advantage.

The concept of business analytics is new in the IS literature. In order to better define this concept, we first discuss business analytics and its evolution. Since our aim is to build a theory analysing the competitive advantage provided by business analytics, we follow this with a discussion of the concept of competitive advantage. We then analyse the topic of theory building by presenting a brief literature review, and several recommendations from the literature are reviewed for the impact they might have on theory building for business analytics. Finally, we briefly analyse theories from relevant parent disciplines and the contribution they might make to theory building in business analytics.

\section{Business Analytics}

Business analytics involves acquiring new knowledge through an analysis of data and information from various sources, and employing that knowledge to develop and implement value-creating competitive actions (Sharma et al., 2010). The data analysed often reside in integrated databases and data warehouses and the analysis is often conducted employing tools such as data mining, visualisation, online analytical processing, statistical and quantitative analysis, and explanatory and predictive models.

Recent IS research in business analytics suggests that there is a statistically significant relationship between analytical capabilities and supply chain performance (Trkman et al., 2010). From a supply chain management perspective, business analytics is defined as 'a group of approaches, organisational procedures and tools used in combination with one another to gain information, analyse that information, and predict outcomes of problem solutions in any of the four areas (Plan, Source, Make, Deliver)' (Trkman et al., 2010, p. 318). Improving supply chain performance involves complex management processes such as identifying measures, defining targets, planning, communication, monitoring, reporting and feedback. This leads to the conclusion that making profitable business decisions based on very large volumes of internal and external data is only possible with business analytics that enables the analysis of data gathered in vast quantities on a regular basis (Trkman et al., 2010).

\section{Evolution of Business Analytics}

Using available information to aid decision making is natural for human beings. To understand how businesses are developing this capability, March and 
Hevner (2007) use general systems theory to first understand what a business is from an economic point of view. They describe businesses as systems for transforming lower-valued resources acquired from the environment into higher-valued goods and services for the environment. With profit making as the primary motive, it becomes important that organisations systematically acquire relevant information to make better decisions and stay ahead of their peers. Data warehouses are playing the role of information processors by integrating, interpreting and transforming the data for managerial decision making (March and Hevner, 2007). A data warehouse can be metaphorically thought of as a facilitating manager, helping to better understand the business problems, opportunities and performance avenues.

Another IS innovation linked with gathering data is enterprise resource planning (ERP). The widespread implementation of ERP systems helps organisations to integrate their information and make the integrated information readily available for further use. The implementation of ERP systems along with the improvement and adoption of data warehousing technology can help decision support systems to access customised data. But there are two important issues that need to be addressed before ERP systems can be used in decision support systems. The first is that ERP systems are built from a transaction processing point of view and hence can provide only ad-hoc decision support at best (Seethamraju, 2007). To cover this gap, organisations are increasingly bolting a decision support system on top of their existing ERP systems (Seethamraju, 2007). The second issue concerns external information, which is often very relevant in aiding strategic decisions and is typically not captured in an ERP environment, thus limiting the use of ERP for operational decision support.

With advances in online analytical processing (OLAP) and data-mining tools, data warehouses are becoming increasingly efficient in analysing and reporting. Analysing structured data has become relatively easy. There are numerous other information sources that are unstructured or at best semi-structured (email, web pages, research papers, reports, and so on). Often overlooked and under-utilised, these sources are nevertheless important in ensuring the quality of decision making and, as finding, organising and analysing these sources is difficult, mastering this is quite likely to give greater competitive advantage to a firm that does so. Recently IS researchers have focused on assimilating semi-structured and unstructured data with the structured data to provide a comprehensive view for strategic decision making, with Baars and Kemper (2008) prescribing three approaches in this area.

The three approaches identified by Baars and Kemper (2008) vary from a simple integrated presentation of different types of data sources to applying complex knowledge management techniques to diffuse relevant data across the organisation. The first approach is called 'integrated presentation', where 
both structured and unstructured data can be simultaneously accessed via an integrated user interface. The second approach is called 'analysis of content collection', where it is possible to analyse unstructured data based on its metadata (date of creation, length, author, and so on). The third approach is called 'distribution of analysis results and analysis templates', where it is presupposed that there is business intelligence knowledge that is of relevance to users and that can be efficiently shared. Moreover, even if the concrete results are too specific for immediate reuse, the process of deriving those results (analysis model used, selected data sources, visualisations used, and so on) might be useful for other users. The choice of a particular approach is based on the relative business potential of integrating varied data sources using the different approaches (Baars and Kemper, 2008).

Apart from the technical issues, IS research has also focused on the problems faced by managers after implementation of a business intelligence or business analytics system. A technically successful implementation does not necessarily lead to desired benefits. Several practical issues have to be monitored when organisations are using the system. New information needs, change in organisational focus and unexpected market developments among other factors are the realities of a dynamic business environment (Dekkers et al., 2007). A greater focus on organising a business intelligence/business analytics system initiative to answer the dynamic information needs of business users is required.

\section{Competitive Advantage}

Among other things, the development of business analytics as a tool is enmeshed in an organisation's use of other new and innovative information technology (IT) tools. Therefore, before researching the role of business analytics in creating a competitive advantage, it would be beneficial to understand how IT has been traditionally employed in trying to build competitive advantage. It can be argued that investment in information technology helps to facilitate and enhance the work done by an organisation but not all IT products developed by an organisation are useful, and in some cases they can leave a deep hole in the pockets of investing companies. Carr (2004) goes to one extreme by arguing that IT, which requires a lot of investment and often does not provide any competitive advantage, has become a commoditised entity in today's corporate world.

\section{IT and Competitive Advantage}

With many IT projects failing to deliver their promised results, IS researchers have focused their energy towards finding the causes. The first consensus 
reached was that stand-alone investment in IT will not necessarily lead to any addition of economic value. Information technology networks and databases can be easily procured from the technology market and hence are unlikely to be the source of a distinct competitive advantage. Much focus is required on 'the configuration of an activity system, dependent on IT at its core, which fosters the creation and appropriation of economic value' (Piccoli and Ives, 2005, p. 748). But even with the effective implementation of IT, organisations are now concerned about the easy imitability of their IT initiatives as new and improved off-the-shelf products are made available to their competitors. Quick obsolescence is another problem fuelled by the fast-paced innovation in IT offerings. In this dynamic world of IT, maintaining a competitive advantage is becoming increasingly difficult.

There is a plethora of literature that talks about how organisations can use IT to create competitive advantage. Piccoli and Ives (2005, p. 751) take the resourcebased view to identify four barriers to erosion of competitive advantage that might be established. These barriers are the 'IT resources barrier, complementary resources barrier, IT project barrier and pre-emption barrier'. Ravichandran and Lertwongsatien (2005) measure firm performance by analysing how IT is used effectively to support and enhance the firm's core competencies. They recognise that firm resources are the main drivers of firm performance and suggest using IT to reinforce firm resources, thus creating complementary resources. Bhatt and Grover (2005, p. 253) discuss whether IT can be used to provide differential benefits to individual firms. They frame 'value, competitive and dynamic capabilities' as three distinct types of capabilities and describe the relationship between these capabilities and competitive advantage.

\section{Business Analytics and Competitive Advantage}

While the research on IT and competitive advantage is still evolving, a parallel discussion on gaining competitive advantage through the use of the vast amounts of data held by today's organisations has gained momentum. According to Davenport (2006), businesses today are offering similar types of products using comparable technologies, which renders competing on business processes alone unviable. He provides various instances where business analytics is being used in a variety of sectors like entertainment (Harrah's), finance (Capital One), e-commerce (Amazon), logistics (UPS), consumer products (P\&G) and retail (WalMart). He further argues that business analytics has helped these companies to intelligently use their existing data sources so as to aid decision making and build a remarkable competitive advantage.

A common claim across sectors is that the use of business analytics has a direct positive impact on competitive advantage. Analysing such intelligent use of data 
sources is a complex and evolving research stream. Given the need of businesses to effectively utilise their data, future research in IS should focus on explaining how companies can best use their data to build competitive advantage.

Since business analytics is a relatively new term, a lot of scope exists for conceptualising this area and theorising about how it can provide competitive advantage for organisations, so the next section presents some suggestions from the IS literature on theory building and how these can be used in our future endeavours to theorise about the competitive advantage provided by business analytics.

\section{Theory Building for Business Analytics}

Given the substantial recent focus on publishing 'good theory' papers, researchers nowadays are highly motivated to build a theory in their field. But, in order to build a strong theory, researchers need to take care of several aspects, which include: presenting logical arguments explaining the empirical relationships found in the data, explaining the strong predictive capabilities of certain variables, explaining the proposed causal or other connections (usually in a diagram) and explaining the rationale for a hypothesis. A strong theory 'delves into underlying processes so as to understand the systematic reasons for a particular occurrence or non-occurrence' (Sutton and Staw, 1995, p. 378).

One such theory-building initiative in business analytics was the development of a dynamic business analytics capabilities (DBAC) framework, which aims to explain the competitive advantage provided by business analytics (Sharma et al., 2010). The DBAC model focuses on how knowledge generated by a business analytics infrastructure can be used to create organisational factors and processes that in turn lead to the development and implementation of valuecreating competitive actions. Figure $10.1^{1}$ shows a representation of the DBAC model as conceptualised by Sharma et al. (2010).

A meta-theoretical analysis by Gregor (2006) presents and defines multiple views of theory in information systems. It furthers the argument that 'theories are practical' because of the systemic manner in which knowledge is accumulated and is made available for professional practice. The 'systematic manner of knowledge accumulation' is described by identifying the nature of five types of IS theory (analysis, explanation, prediction, explanation and prediction, and design and action). Accordingly, a good theory in business analytics should

1 Figure used with permission from the original authors. 
strive to present knowledge about business analytics in a 'systematic manner' through the use of various factors (variables, constructs, concepts, and so on) whatever position it occupies in Gregor's typology.

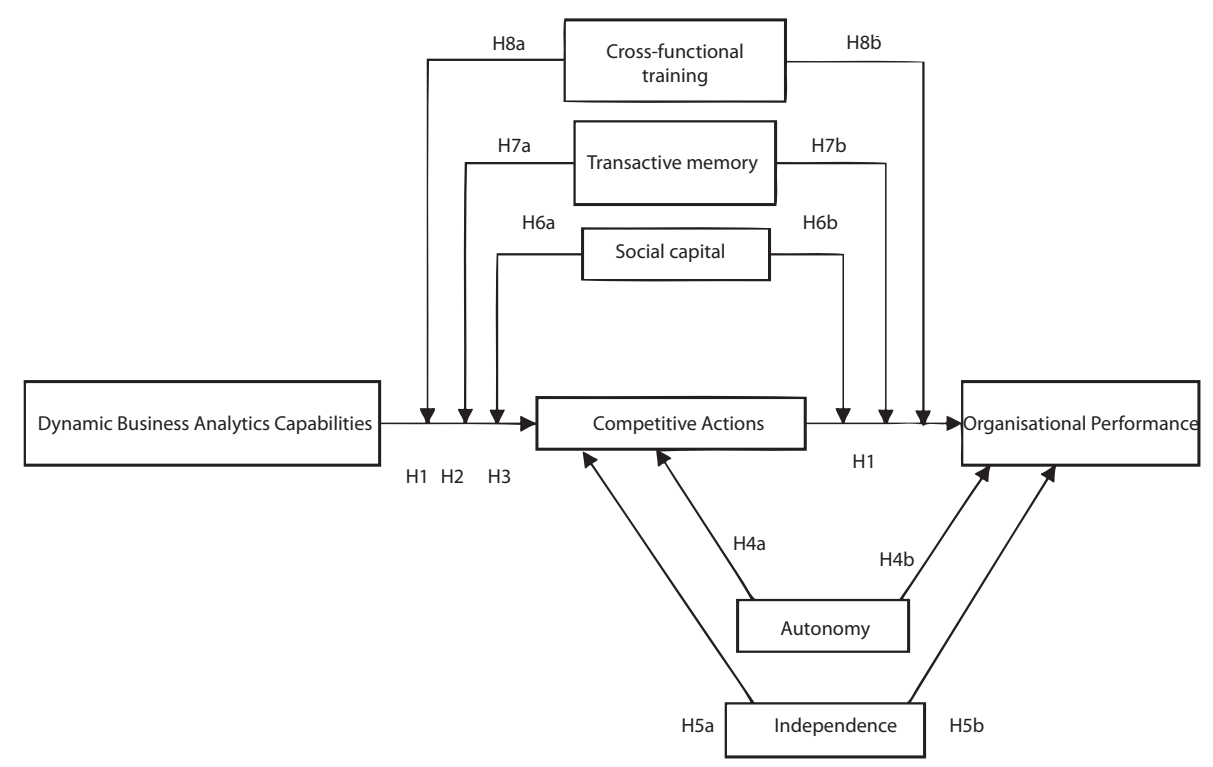

\section{Figure 10.1 The Dynamic Business Analytics Capabilities (DBAC) Model}

In order to achieve a 'complete' theory, as defined by Whetten (1989), it is necessary to take care of four essential elements. We now analyse the DBAC theory presented by Sharma et al. (2010) with respect to these four essential elements. First, we have to identify certain factors (variables, constructs, concepts) that would be the key elements for building a theory in business analytics (the 'what' element). From a technological perspective, these factors could be data warehousing, business intelligence, decision support and other systems. In the DBAC model, several organisational factors like cross-functional training, transactive memory, social capital, autonomy and independence are identified, which in turn are linked to a dependent variable called organisational performance.

Second, we need to describe the relationships among the identified factors (the 'how' element). Such relationships can be based on observations from industry, anecdotes and other forms of cognition. In the DBAC model, relationships between the factors are proposed in the form of several logically derived hypotheses (Sharma et al., 2010). Third, it is necessary to justify the selection of these few factors and the relationships between them (the 'why' element). This involves explaining the choice of factors and causal relationships logically to peers, for further scrutiny. The DBAC model argues that dynamic capabilities are independent of IT investment (Sharma et al., 2010). This assumption helps 
the authors to justify their focus on organisational factors. Further, the authors provide logical arguments for the selection of organisational parameters that might affect the firm's competitive advantage. Fourth, setting boundaries about the generalisability of the theory helps to justify the scope of theory (the 'who, where, when' element). Generalisability becomes an important topic when we consider the practical applicability of a theory.

In their business analytics research, Sharma et al. (2010) use deductive logic to construct their DBAC model. They draw on the literature on dynamic capabilities and define DBAC as a specific dynamic capability that utilises the operational and other data available in an organisation's information assets to develop resources and implement value-creating competitive actions (Sharma et al., 2010). Although the DBAC model identifies the key factors necessary to achieve performance gains from business analytics, there still is a need to empirically test the framework in industry settings. The scope of the DBAC model would be set out in the empirical testing phase where the testers would define the testing environment. This testing environment could then shape the generalisability of the DBAC model to other environments.

Evidence of the use of business analytics is present in multiple industries (Davenport, 2006). The ways to approach theory building in business analytics also vary, from the use of the dynamic capabilities literature in the DBAC model (Sharma et al., 2010) to the use of the supply chain management literature (Trkman et al., 2010). This implies that theories developed for business analytics might have to cater to a wide variety of industries, making the research more interdisciplinary. Researchers will have to be careful when generalising business analytics theories from one topic area to another.

A type of descriptive analysis can be undertaken to understand the practice of business analytics in industry. This effort can be classified as theory for analysis (Gregor, 2006), and empirical techniques like surveys and interviews can be used for exploration. At the same time, there is a need for qualitative analysis in this field, which among other things would talk about the perceived impact of business analytics in an organisation.

\section{Theoretical Orientation from Parent Fields}

It is evident that the development of information systems in areas like data mining, decision support systems, data warehousing and business intelligence has collectively shaped the business analytics arena (Davenport, 2006). Given this, well-established theories in these parent fields are likely to influence theory building in business analytics. One example is the 'multi-layer framework for business intelligence'. 
The multi-layer framework for business intelligence conceptualised by Baars and Kemper (2008) is an important business intelligence framework that maps the logical business intelligence (BI) components and their core interrelations. It is important for future theory-building efforts in business analytics because this framework suggests how data can be collected from various sources, stored, analysed and distributed to relevant users. A business analytics researcher could take the concept further by theorising about how, after receiving the required information, users could employ it to gain competitive advantage in the marketplace. The framework was developed over the course of several years in tight interaction with practitioners from both the supply and the application sides (Baars and Kemper, 2008).

The framework distinguishes three layers: data, logic and access. The data layer is responsible for storing structured and unstructured data for management support functions. Usually, structured data are kept in special data repositoriesdata warehouses, data marts and operational data stores - while unstructured content is handled with content and document management systems. The data are extracted from source systems, which might include operational systems like ERP or SCM systems and external data sources (Baars and Kemper, 2008).

The logic layer provides functionality to analyse structured data or unstructured content and supports the distribution of relevant knowledge. The analytical functionality of the logic layer not only includes OLAP and data mining but also functionality to generate (interactive) business reports and perform ad-hoc analysis (Baars and Kemper, 2008). The access layer allows a user to conveniently access all relevant functions of the logic layer in an integrated fashion within the confines of defined user roles and user rights. Usually the access layer is realised with some sort of portal software that provides a harmonised graphical user interface (Baars and Kemper, 2008).

\section{Conclusion}

We argue that business analytics as a construct has not been properly defined in the literature yet so we have tried to provide some insight in this area. Nevertheless, further work needs to be done in order to analyse how various parent fields can contribute to the development of business analytics. Various aspects of theory building have also been reviewed and the role this literature could play in guiding theory-building initiatives for business analytics is also briefly analysed. Our aim is not to prescribe any particular method but rather to make researchers aware of what is recommended in the existing literature and how it can be used for research in business analytics. 


\section{References}

Baars, H., \& Kemper, H.-G. (2008). Management support with structured and unstructured data-an integrated business intelligence framework. Information Systems Management, 25(2), 132-48.

Bhatt, G. D., \& Grover, V. (2005). Types of information technology capabilities and their role in competitive advantage: an empirical study. Journal of Management Information Systems, 22(2), 253-77.

Carr, N. G. (2004). IT doesn't matter. IEEE Engineering Management Review, $32(1), 24-32$.

Davenport, T. H. (2006). Competing on analytics. Harvard Business Review, 84(1), 99-107.

Dekkers, J., Versendaal, J., \& Batenburg, R. (2007). Organising for business intelligence: a framework for aligning the use and development of information. Proceedings of the $20^{\text {th }}$ Bled eConference eMergence, Bled, Slovenia, 625-36.

Gregor, S. (2006). The nature of theory in information systems. Management Information Systems Quarterly, 30(3), 611-42.

Kohavi, R., Rothleder, N. J., \& Simoudis, E. (2002). Emerging trends in business analytics. Communications of the ACM, 45(8), 45-8.

March, S. T., \& Hevner, A. R. (2007). Integrated decision support systems: a data warehousing perspective. Decision Support Systems, 43(3), 1031-43.

Piccoli, G., \& Ives, B. (2005). Review: IT-dependent strategic initiatives and sustained competitive advantage: a review and synthesis of the literature. MIS Quarterly, 29(4), 747-76.

Ravichandran, T., \& Lertwongsatien, C. (2005). Effect of information systems resources and capabilities on firm performance: a resource-based perspective. Journal of Management Information Systems, 21(4), 237-76.

Seethamraju, R. (2007). ERP systems and decision support-an exploratory study. Proceedings of the International Conference on Decision Support Systems (!CDSS 2007).

Sharma, R., Reynolds, P., Scheepers, R., Seddon, P., \& Shanks, G. (2010). Business analytics and competitive advantage: a review and a research agenda. Paper presented at the Fifth International Federation of Information Processing WG 8.3 International Conference on Decision Support Systems, Lisbon, Portugal. 
Sutton, R., \& Staw, B. (1995). What theory is not. Administrative Science Quarterly, 40(3), 371-84.

Trkman, P., McCormack, K., de Oliveira, M. P. V., \& Ladeira, M. B. (2010). The impact of business analytics on supply chain performance. Decision Support Systems, 49(3), 318-27.

Whetten, D. A. (1989). What constitutes a theoretical contribution? Academy of Management Review, 14(4), 490-5. 